\title{
Association of traumatic brain injury with subsequent neurological and psychiatric disease: a meta-analysis
}

\author{
David C. Perry, MD, ${ }^{1}$ Virginia E. Sturm, PhD, ${ }^{1}$ Matthew J. Peterson, PhD, ${ }^{4,5}$ Carl F. Pieper, DPH, ${ }^{6}$ \\ Thomas Bullock, MD, ${ }^{3}$ Bradley F. Boeve, MD, ${ }^{8}$ Bruce L. Miller, MD, ${ }^{1}$ \\ Kevin M. Guskiewicz, PhD, ATC, ${ }^{9}$ Mitchel S. Berger, MD, ${ }^{2}$ Joel H. Kramer, PsyD, ${ }^{1}$ and \\ Kathleen A. Welsh-Bohmer, $\mathrm{PhD}^{7}$
}

Departments of ${ }^{1}$ Neurology and ${ }^{2}$ Neurosurgery; ${ }^{3}$ UCSF School of Medicine, University of California, San Francisco, California; ${ }^{4}$ Geriatric Research, Education, and Clinical Center, Veterans Affairs Medical Center; Departments of ${ }^{5}$ Medicine, ${ }^{6}$ Biostatistics and Bioinformatics, and ${ }^{7}$ Psychiatry and Behavioral Sciences, Duke University, Durham, North Carolina; ${ }^{8}$ Department of Neurology, Mayo Clinic, Rochester, Minnesota; and 'Department of Exercise and Sport Science, University of North Carolina, Chapel Hill, North Carolina

OBJECTIVE Mild traumatic brain injury (TBI) has been proposed as a risk factor for the development of Alzheimer's disease, Parkinson's disease, depression, and other illnesses. This study's objective was to determine the association of prior mild TBI with the subsequent diagnosis (that is, at least 1 year postinjury) of neurological or psychiatric disease.

METHODS All studies from January 1995 to February 2012 reporting TBI as a risk factor for diagnoses of interest were identified by searching PubMed, study references, and review articles. Reviewers abstracted the data and assessed study designs and characteristics.

RESULTS Fifty-seven studies met the inclusion criteria. A random effects meta-analysis revealed a significant association of prior TBI with subsequent neurological and psychiatric diagnoses. The pooled odds ratio (OR) for the development of any illness subsequent to prior TBI was $1.67(95 \% \mathrm{Cl} 1.44-1.93, \mathrm{p}<0.0001)$. Prior TBI was independently associated with both neurological $(\mathrm{OR} 1.55,95 \% \mathrm{Cl} 1.31-1.83, \mathrm{p}<0.0001)$ and psychiatric (OR 2.00, 95\% Cl 1.50-2.66, $\mathrm{p}$ $<0.0001$ ) outcomes. Analyses of individual diagnoses revealed higher odds of Alzheimer's disease, Parkinson's disease, mild cognitive impairment, depression, mixed affective disorders, and bipolar disorder in individuals with previous TBI as compared to those without TBI. This association was present when examining only studies of mild TBI and when considering the influence of study design and characteristics. Analysis of a subset of studies demonstrated no evidence that multiple TBIs were associated with higher odds of disease than a single TBI.

CONCLUSIONS History of TBI, including mild TBI, is associated with the development of neurological and psychiatric illness. This finding indicates that either TBI is a risk factor for heterogeneous pathological processes or that TBI may contribute to a common pathological mechanism.

http://thejns.org/doi/abs/10.3171/2015.2.JNS14503

KEY WORDS dementia; psychiatry; head injury; meta-analysis; traumatic brain injury

$\mathrm{S}$ INCE the 1928 description of the "punch drunk" condition, ${ }^{48}$ there has been speculation about a connection between traumatic brain injury (TBI) and late-life neurological or psychiatric illness. Though this syndrome was later referred to as "dementia pugilistica" because it was thought to uniquely affect boxers, ${ }^{14}$ an accumulation of cases in recent years has suggested that repeated brain injury in other sports, such as football, soccer, and wrestling, might also predispose to neurodegenerative disease $^{52}$ and that nonsports-related TBI, such as that sustained on the battlefield, can lead to this same illness.$^{30} \mathrm{It}$ has recently been proposed that a history of even minor brain injury can predispose certain individuals to develop this pathological process, now referred to as "chronic traumatic encephalopathy" (CTE) ${ }^{52}$ The presentation of CTE is variable and can include neurological and/or psychiatric manifestations. The current CTE literature suggests 2 common syndromes: a behavior- and mood-predominant

ABBREVIATIONS ALS = amyotrophic lateral sclerosis; $\mathrm{Cl}=$ confidence interval; $\mathrm{CTE}=$ chronic traumatic encephalopathy; LOC = loss of consciousness; OR = odds ratio; $\mathrm{TBI}=$ traumatic brain injury.

SUBMITTED March 5, 2014. ACCEPTED February 26, 2015.

INCLUDE WHEN CITING Published online August 28, 2015; DOI: 10.3171/2015.2.JNS14503. 
illness frequently accompanied by paranoia, which would be diagnosed as a psychiatric illness, and a predominantly cognitive disorder that is frequently diagnosed as Alzheimer's disease. ${ }^{82} \mathrm{~A}$ third syndrome, which was emphasized in the prior literature on boxers, includes motor dysfunction with parkinsonism. ${ }^{14}$ Some CTE cases have also been described with motor neuron disease..$^{53,54}$ The epidemiological study of CTE has been significantly limited since it is a pathological rather than a clinical diagnosis and its presence can only be definitively confirmed after death. However, there is accumulating evidence that CTE may be a pathological process that unites seemingly disparate clinical syndromes and reflects a shared vulnerability to cognitive-behavioral-motor dysfunction. Recent studies have found support for a relationship between TBI and the risk for later development of these individual neurological and psychiatric syndromes. Since James Parkinson himself theorized a causative link to trauma in 1817, there has been continuing debate regarding the relationship between TBI and Parkinson's disease, ${ }^{19}$ with many ${ }^{17,29,87}$ but not all ${ }^{3,43,49}$ studies finding a positive association. Epidemiological studies investigating the risk of Alzheimer's disease after TBI have also shown mixed results. Meta-analyses of these studies in $1991^{58}$ and in $2003^{24}$ have shown an elevated risk. Prior TBI has also been associated with a significantly elevated risk of frontotemporal dementia, ${ }^{70}$ and although a prior meta-analysis of the relationship between prior TBI and the subsequent development of amyotrophic lateral sclerosis (ALS) showed a mildly elevated risk,,$^{11}$ others have disputed the connection. ${ }^{93}$ Although psychiatric symptoms (for example, depression and anxiety) are common acutely after TBI, ${ }^{6,35,40}$ whether there are protracted psychiatric sequelae from earlier-life TBI remains poorly understood. ${ }^{96}$

Our aim was to clarify the association between mild TBI and the later development of those neurological and psychiatric illnesses that have been linked to TBI and are potential manifestations of CTE. To investigate the wide range of disorders associated with prior TBI, we reviewed the literature examining TBI and subsequent neurological or psychiatric diagnoses and performed a meta-analysis according to current guidelines. ${ }^{56,84}$ Given the notion that mild TBI may make certain individuals vulnerable to a number of neurological and psychiatric conditions, we hypothesized that there would be an association between all diagnoses and a history of TBI, including mild TBI.

\section{Methods}

\section{Identification of Studies}

Searches were conducted in MEDLINE (January 1995 to February 2012) using a comprehensive search strategy. We used 2 components in each search: component A identified papers with the key words "craniocerebral trauma," "head injury," "brain injury," or "concussion." This was combined with component B or C. Component $\mathrm{B}$ identified papers pertaining to the neurological disorders of interest (that is, "neurodegenerative diseases," "mild cognitive impairment," "Alzheimer," "Parkinson," "frontotemporal dementia," "amyotrophic lateral sclerosis," "vascular dementia," or "dementia"), and component
$\mathrm{C}$ identified papers pertaining to the psychiatric illnesses of interest (that is, "anxiety disorders," "mood disorders," or "schizophrenia and disorders with psychotic features"). We limited our search to papers in English and in humans.

Three additional steps were taken to ensure search comprehensiveness: 1) references from included papers were reviewed; 2) to avoid any bias toward positive results inherent in the search strategy, an additional search for "risk factors" for each diagnosis was performed to capture studies with weak or null findings that did not include our search terms in their title, abstract, or key words; and 3 ) the citation lists in review papers were examined. For papers in which the required metrics were not easily identified, the authors were contacted. A pair of reviewers (a neurologist and a neuropsychologist) discussed all papers at each stage of the process (Fig. 1). Concordance between the reviewers for determining study inclusion was high; in cases of disagreement, studies were discussed until a consensus decision was reached. Ethics committee approval was not needed for this study as it included only analysis of previously published data.

\section{Broad Inclusion Criteria}

We first applied broad inclusion criteria (developed by a team of expert neurologists, neurosurgeons, and neuropsychologists) to select papers for further review: original, peer-reviewed research articles (no case reports); subjects older than 18 years of age at the time of evaluation (not TBI); TBI without accompanying structural lesion (for example, subdural hematoma or penetrating brain injury; although our goal was to specifically examine the effect of mild TBI, to capture all pertinent studies at this search stage, we broadly included studies employing the various definitions and labels that are used to refer to minor head trauma, for example, concussion); neurological or psychiatric diagnosis; and TBI occurred before the diagnosis of the neurological or psychiatric disorder (with at least 12 months between the TBI and outcome diagnosis, if specified).

\section{Narrow Inclusion Criteria}

Papers that met the broad inclusion criteria were next reviewed in detail. In addition to ensuring adherence to the broad criteria, we confirmed that papers met the narrow inclusion criteria. If some subjects in a study were reported to have structural lesions, but they could be separated from those without lesions, we included only those subjects with mild TBI. The narrow inclusion criteria consisted of the following: 1) the presence of a neurological or psychiatric disorder. For neurological disorders, studies must have used consensus diagnostic criteria or clinical evaluation. For psychiatric disorders, diagnoses were based on either criteria (for example, those in the Diagnostic and Statistical Manual of Mental Disorders, 4th Edition) or scores from standardized measures (for example, Beck Depression Inventory). 2) The study had a control group. Included studies were cross-sectional, cohort, or case-control studies in which all subjects underwent identical assessment and diagnostic procedures. 3) The TBI preceded the neurological or psychiatric diagnosis. We ex- 


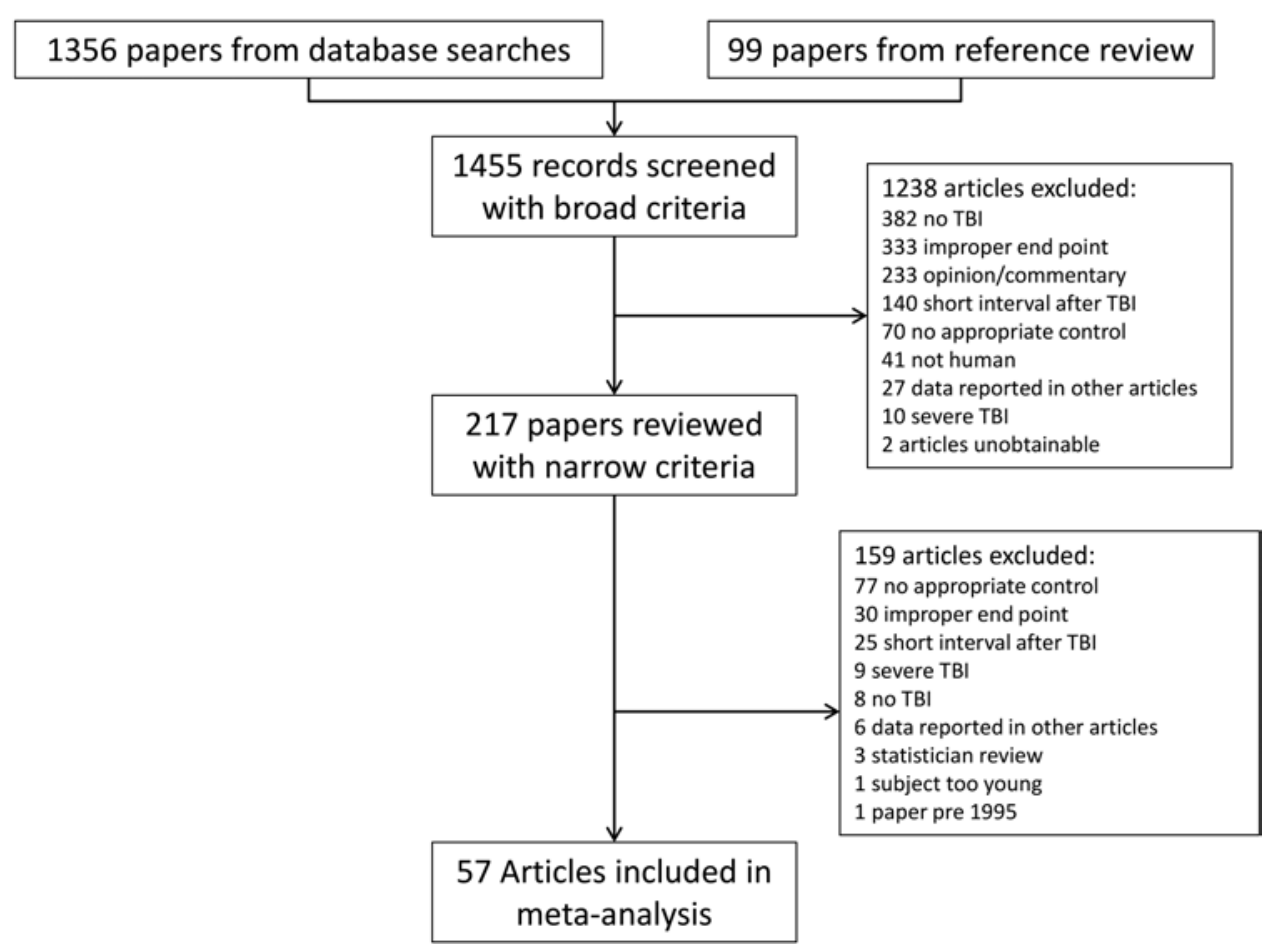

FIG. 1. Flowchart depicting study identification and screening.

cluded studies in which the diagnosis of the neurological or psychiatric disorder had been made less than 12 months post-TBI. For studies in which the date of the TBI was not reported, we included only those whose subjects with neurological or psychiatric illness had been asked about TBI earlier in life. 4) There could be no redundant subjects across studies. In cases where multiple papers used the same study cohort, we included the most recent papers to capture the largest sample size. If multiple outcome diagnoses were reported in 1 paper, we included each odds ratio $(\mathrm{OR})$ if the diagnoses were mutually exclusive. If the diagnoses were not mutually exclusive, in the analyses that examined the association of TBI with any neurological or psychiatric outcome, we chose the broader diagnosis (for example, dementia was preferred over Alzheimer's disease), or if that distinction was not possible, we chose the diagnosis with the larger number of subjects.

\section{Assessment of Study Characteristics}

We recorded additional data regarding factors that could influence the relationship between TBI and outcome diagnoses, including 1) the rigor with which each study employed a 12-month TBI-outcome diagnosis interval; 2) the TBI characteristics required in each study (for example, whether subjects met accepted criteria for mild TBI or had any individual symptoms such as loss of consciousness [LOC]); 3) whether the TBI diagnosis was based on patient or informant self-report as opposed to being made by a clinician, derived from medical records, or based on diagnostic criteria; 4) the study design (cohort, case-control, or cross-sectional); and 5) whether information was provided about the number of TBIs sustained by each subject. These data were used in subgroup analyses geared toward assessing whether study characteristics influenced the meta-analysis results.

\section{Statistical Analysis}

Primary Analyses

The effect of interest for this meta-analysis was the pooled OR. For the majority of the studies (51 of 57), unadjusted ORs were directly calculated from data extraction. Standard errors were calculated from the logarithm of the OR to allow for symmetry of the estimate on both sides of unity. ${ }^{23}$ Where sample sizes were not available, the published unadjusted ORs were used. We then applied standard meta-analytical techniques, ${ }^{34}$ including weighted estimates of the pooled OR with a 95\% confidence interval (CI). For those studies in which the raw cell frequencies did not exist and only the standard error of the OR was available, to provide appropriate weighting of the study in the meta-analysis, the standard error of the OR was transformed to the standard error of the logarithm of the OR by linear interpolation. To determine whether there was significant variation among studies, tests of heterogeneity were performed. ${ }^{34}$ All analyses were conducted using SAS version 9.3 (SAS Institute Inc.). A p value $<0.05$ was significant.

\section{Subgroup Analyses}

Since the overall analysis was inclusive of various TBI definitions and study characteristics, we conducted 7 additional subgroup analyses to determine whether our results differed when pooling studies with more uniformity of TBI assessment, TBI diagnostic criteria, and study de- 
sign. When possible, we selected only those subjects from the overall cohort who met the criteria for each subgroup analysis. Consequently, for some studies, a different number of subjects was included in the overall analysis compared with each subgroup analysis.

Subgroup 1: Effect of Time Interval Between TBI and Diagnosis. To ensure that studies with less stringent guidelines about the timing of TBI were not significantly impacting our results, in Subgroup 1 we excluded analyses in which the subjects had possibly less than a 12-month interval between TBI and a diagnosis.

Subgroups 2-4: Effect of TBI Features and Severity. Subgroup 2 included only studies that required an LOC not exceeding 30 minutes. This is the maximum duration established in the mild TBI criteria of the American Congress of Rehabilitation Medicine, Centers for Disease Control, and World Health Organization. . $^{10,42,59}$

Subgroup 3 included only studies that required brain injury with LOC. This subgroup considered the effect of TBI with a uniform minimum severity.

In Subgroup 4, to exclude extremely mild or asymptomatic brain injury, we performed an analysis of studies that required the brain injury to be accompanied by any 1 (or more than 1) common feature of mild TBI, including LOC, posttraumatic amnesia, Glasgow Coma Scale (GCS) score $\geq 13$, focal neurological deficit, altered mental status, brain injury requiring medical care, or symptoms of the postconcussive syndrome (for example, headache, dizziness, nausea, photo- or phonophobia, fatigue, sleep difficulty, blurred vision).

Subgroups 5-6: Effect of Study Design. In Subgroup 5, to assess the impact of recall bias, we conducted an analysis excluding studies with self-reported TBI. In Subgroup 6 , to eliminate recall bias, we also performed an analysis of only cohort studies (rather than cross-sectional or casecontrol studies).

Subgroup 7: Effect of Number of TBIs. Because we were also interested in whether there is a dose effect of TBI on the development of later illness, in Subgroup 7 we calculated the odds of a neurological or psychiatric diagnosis in subjects with more than 1 versus a single TBI using a subset of studies that provided this information.

\section{Publication Bias Analysis}

To assess for the effect of publication bias on our results, we used the Egger method ${ }^{18}$ to examine whether the logarithm of the included ORs were predicted by the standard error, which reflects the sample size. We visually examined funnel plots of ORs against sample size and the logarithm of the ORs against the standard error of the logarithm of the ORs and quantified the degree of bias by multiple regressions. Using standard error rather than sample size in funnel plots may provide a more accurate visual depiction of whether bias is present. ${ }^{83}$

\section{Results}

Fifty-seven papers met the narrow inclusion criteria

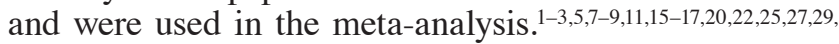
$31-33,37,43,45,47,49,51,55,57,60-65,67-76,79-81,85-87,90-95,97,98$ Among the in- cluded papers, a sufficient number were found to apply meta-analytical methods for the diagnoses of dementia, Alzheimer's disease, Parkinson's disease, ALS, mild cognitive impairment, depression, psychotic disorders, bipolar disorder, and mixed affective disorder (a combined group of depression and anxiety). Insufficient numbers of studies were found to calculate a pooled OR for frontotemporal dementia, vascular dementia, or anxiety disorders. There was significant heterogeneity among studies $(\mathrm{Q}=381.99$, $\mathrm{df}=58, \mathrm{p}<0.001$ ), justifying the use of the random-effects meta-analysis.

Prior TBI was associated with the development of any of the neurological and psychiatric illnesses of interest (OR $1.67,95 \%$ CI $1.44-1.93, \mathrm{p}<0.0001)$. This association was found for both neurological (OR 1.55, 95\% CI 1.31-1.83, $\mathrm{p}<0.0001)$ and psychiatric (OR 2.00, 95\% CI 1.50-2.66, $\mathrm{p}<0.0001$ ) diseases in individuals with TBI and was also found for the following diagnoses: Alzheimer's disease (OR 1.40, 95\% CI 1.02-1.90, p < 0.05), Parkinson's disease (OR 1.45, 95\% CI 1.18-1.78, p < 0.001), mild cognitive impairment (OR 2.69, 95\% CI 1.51-4.77, p < 0.001), depression (OR 2.14, 95\% CI 1.65-2.77, p < 0.0001), bipolar disorder (OR 1.85, 95\% CI 1.17-2.94, $\mathrm{p}<0.01$ ), and mixed affective disorder (OR 1.84, 95\% CI 1.50-2.66, $\mathrm{p}<$ 0.0001; Table 1 and Fig. 2).

Analyses of subgroups revealed a robust relationship between TBI and remote neurological and psychiatric outcomes. The studies included in each subgroup analysis are specified in Table 1. Table 2 includes the features reported in each study regarding the time interval between TBI and diagnosis, the TBI features and severity, and the study design. Results of the subgroup analyses are reported in Table 3. Overall odds and the independent ORs for neurological, but not psychiatric, disease remained significant when including only studies with the clearest interval longer than 12 months between TBI and diagnosis (Subgroup 1). The overall OR was significant among studies that adhered to mild TBI criteria limiting the duration of LOC to less than 30 minutes (Subgroup 2). The overall OR and the ORs for any of the studied neurological and psychiatric diagnoses were also significant when including only studies that required LOC (Subgroup 3). When including studies that required the presence of at least 1 mild TBI symptom (Subgroup 4), the overall OR and the OR for any of the neurological and all psychiatric diagnoses of interest remained significant. After eliminating studies with TBI diagnoses based on self-reports (Subgroup 5), the overall OR and the OR for neurological disorders remained significant, although the OR for psychiatric outcomes no longer reached significance. When only cohort studies were included (Subgroup 6), the OR for neurological outcomes was not significant, although the overall OR and the OR for psychiatric illness remained significant. The odds were not higher among studies that reported more than 1 TBI versus those with a single injury (Subgroup 7).

Publication bias analyses did not show evidence of bias in the included studies. Visual inspection of a funnel plot based on sample size showed that 3 studies with large samples strongly influenced the appearance of the plot (Fig. 3A). When these 3 studies were removed, a more expected funnel shape could be appreciated (Fig. 3B). Re- 
TABLE 1. Individual and pooled ORs for all included studies

\begin{tabular}{|c|c|c|c|c|}
\hline Authors \& Year & Cases (no. w/ TBI/no. w/o TBI) & Controls (no. w/ TBI/no. w/o TBI) & OR & $95 \% \mathrm{Cl}$ \\
\hline \multicolumn{5}{|l|}{ Neurological diagnosis } \\
\hline \multicolumn{5}{|l|}{ Dementia } \\
\hline Salib $1997^{\mathrm{b}, \mathrm{c}, \mathrm{d}, \mathrm{e}}$ & $96 / 266$ & $23 / 153$ & 2.40 & $1.46-3.95$ \\
\hline Schofield $1997^{\mathrm{b}, \mathrm{e}, \mathrm{g}}$ & $6 / 41$ & $21 / 198$ & 1.38 & $0.52-3.61$ \\
\hline Mehta 1999d,e,g & $11 / 118$ & $788 / 5728$ & 0.68 & $0.36-1.26$ \\
\hline Plassman $2000^{\mathrm{b}, \mathrm{e}, \mathrm{f}, \mathrm{g}}$ & $28 / 26$ & $520 / 1202$ & 2.49 & $1.45-4.29$ \\
\hline Sundström 2007b,e,h & $25 / 156$ & $46 / 316$ & 1.10 & $0.65-1.86$ \\
\hline Smith $2010^{e}$ & $31 / 14$ & $154 / 164$ & 2.36 & $1.21-4.60$ \\
\hline Tripathi $2012^{\mathrm{e}}$ & $22 / 128$ & $35 / 115$ & 0.56 & $0.31-1.02$ \\
\hline Pooled OR & & & 1.36 & $0.84-2.19$ \\
\hline \multicolumn{5}{|l|}{ Alzheimer's disease } \\
\hline Forster $1995^{b}$ & $25 / 84$ & $22 / 87$ & 1.18 & $0.62-2.25$ \\
\hline Rasmusson $1995^{\mathrm{b}, \mathrm{d}, \mathrm{e}}$ & $20 / 48$ & $1 / 33$ & 13.75 & $1.76-107.53$ \\
\hline Salib 1997a & $53 / 145$ & $23 / 153$ & 2.43 & $1.42-4.17$ \\
\hline Schofield 1997a & $4 / 34$ & $23 / 205$ & 1.05 & $0.34-3.22$ \\
\hline Tsolaki 1997 & $14 / 47$ & $15 / 54$ & 1.07 & $0.47-2.45$ \\
\hline O'Meara 1997b,e & $32 / 317$ & $16 / 326$ & 2.06 & $1.11-3.82$ \\
\hline Boston 1999 & $30 / 192$ & $23 / 117$ & 0.79 & $0.44-1.43$ \\
\hline Mehta 1999a & $6 / 85$ & $788 / 5728$ & 0.51 & $0.22-1.18$ \\
\hline Guo $2000^{e}$ & $394 / 1782$ & $127 / 2313$ & 4.03 & $3.27-4.96$ \\
\hline Plassman 2000a & $17 / 18$ & $520 / 1202$ & 2.18 & $1.12-4.27$ \\
\hline Tyas 2000 & $203 / 821$ & $93 / 605$ & 1.61 & $1.23-2.10$ \\
\hline Lindsay $2002^{g}$ & $28 / 151$ & $603 / 2963$ & 0.91 & $0.60-1.38$ \\
\hline Bachman 2003e & $397 / 1538$ & $84 / 760$ & 2.34 & $1.82-3.00$ \\
\hline Guskiewicz 2005e & $15 / 7$ & $1148 / 732$ & 1.37 & $0.56-3.37$ \\
\hline Ogunniyi Nigeria 20069 & $2 / 60$ & $11 / 450$ & 1.36 & $0.30-6.30$ \\
\hline Ogunniyi USA $2006^{9}$ & $5 / 84$ & $37 / 344$ & 0.55 & $0.21-1.45$ \\
\hline Rippon $2006^{e}$ & $72 / 78$ & $648 / 700$ & 1.00 & $0.71-1.40$ \\
\hline Suhanov $2006^{\mathrm{d}, \mathrm{e}}$ & $46 / 214$ & $30 / 230$ & 1.65 & $1.00-2.71$ \\
\hline Fischer $2008^{g}$ & $4 / 86$ & $37 / 352$ & 0.44 & $0.15-1.27$ \\
\hline Pooled OR & & & 1.40 & $1.02-1.90$ \\
\hline \multicolumn{5}{|l|}{ Parkinson's disease } \\
\hline Martyn $1995^{\mathrm{e}}$ & $11 / 156$ & $35 / 301$ & 0.61 & $0.30-1.23$ \\
\hline De Michele 1996d,e & $13 / 103$ & $3 / 113$ & 4.75 & $1.32-17.16$ \\
\hline Seidler $1996^{e}$ & NA & NA & 1.40 & $0.85-2.30$ \\
\hline McCann 1998d,e & NA & NA & 1.10 & $0.64-1.90$ \\
\hline Smargiassi 1998d,e & $13 / 73$ & $5 / 81$ & 2.88 & $0.98-8.49$ \\
\hline Kuopio 1999d,e,h & $39 / 84$ & $84 / 162$ & 0.90 & $0.56-1.42$ \\
\hline Taylor 1999b,e & $35 / 105$ & $11 / 136$ & 4.12 & $2.00-8.50$ \\
\hline Werneck 1999 & $17 / 75$ & $14 / 96$ & 1.55 & $0.72-3.35$ \\
\hline Tsai $2002^{b, e}$ & $11 / 19$ & $5 / 25$ & 2.89 & $0.86-9.75$ \\
\hline Baldereschi $2003^{d, e, g}$ & $8 / 105$ & $403 / 3980$ & 0.75 & $0.36-1.56$ \\
\hline Bower $2003^{b, c, e, f}$ & $2 / 183$ & 2/193 & 1.05 & $0.15-7.57$ \\
\hline Goldman $2006^{b, c, e, h}$ & $20 / 73$ & $9 / 84$ & 2.56 & $1.10-5.96$ \\
\hline Dick 2007d,e & NA & NA & 1.30 & $1.09-1.55$ \\
\hline Rugbjerg $2008^{\mathrm{b}, \mathrm{e}, \mathrm{f}}$ & $409 / 13,194$ & $1513 / 66,792$ & 1.37 & $1.22-1.53$ \\
\hline Sanyal 2010 & $27 / 148$ & $25 / 325$ & 2.37 & $1.33-4.23$ \\
\hline Pooled OR & & & 1.45 & $1.18-1.78$ \\
\hline
\end{tabular}


TABLE 1. Individual and pooled ORs for all included studies (continued)

\begin{tabular}{|c|c|c|c|c|}
\hline Authors \& Year & Cases (no. w/ TBI/no. w/o TBI) & Controls (no. w/ TBI/no. w/o TBI) & OR & $95 \% \mathrm{Cl}$ \\
\hline \multicolumn{5}{|c|}{ Neurological diagnosis (continued) } \\
\hline \multicolumn{5}{|c|}{ Amyotrophic lateral sclerosis } \\
\hline Chen 2007b,e,h & $24 / 85$ & $42 / 213$ & 1.43 & $0.82-2.51$ \\
\hline Binazzi 2009b & $16 / 61$ & $23 / 162$ & 1.85 & $0.91-3.73$ \\
\hline Schmidt $2010^{b, e, h}$ & $84 / 157$ & $185 / 412$ & 1.19 & $0.87-1.64$ \\
\hline Turner $2010^{\mathrm{b}, \mathrm{e}, \mathrm{f}, \mathrm{g}}$ & $41 / 34$ & $106,552 / 511,831$ & 5.79 & $3.68-9.13$ \\
\hline Pooled OR & & & 2.07 & $0.94-4.56$ \\
\hline \multicolumn{5}{|l|}{ Frontotemporal dementia } \\
\hline Rosso $2003^{b, e}$ & $19 / 61$ & $10 / 114$ & 3.55 & $1.55-8.11$ \\
\hline \multicolumn{5}{|l|}{ Vascular dementia } \\
\hline Boston 1999 & $3 / 31$ & $23 / 117$ & 0.49 & $0.14-1.75$ \\
\hline \multicolumn{5}{|l|}{ Mild cognitive impairment } \\
\hline Guskiewicz 2005e & $19 / 3$ & $450 / 286$ & 4.03 & $1.18-13.73$ \\
\hline Unverzagt $2011 \mathrm{~g}$ & NA & NA & 2.40 & $1.34-4.30$ \\
\hline Pooled OR & & & 2.69 & $1.51-4.77$ \\
\hline Pooled OR, neurological & & & 1.55 & $1.31-1.83$ \\
\hline \multicolumn{5}{|l|}{ Psychiatric diagnosis } \\
\hline \multicolumn{5}{|l|}{ Depression } \\
\hline Malaspina 2001 & $107 / 661$ & $22 / 355$ & 2.61 & $1.62-4.21$ \\
\hline Polusny $2001^{b, c, e, g}$ & NA & NA & 1.47 & $1.10-1.97$ \\
\hline Silver $2001^{e}$ & $40 / 243$ & $321 / 4430$ & 2.27 & $1.60-3.23$ \\
\hline Holsinger $2002^{b, c, e, f, g}$ & $96 / 160$ & $387 / 974$ & 1.51 & $1.14-2.00$ \\
\hline Guskiewicz 2007e & $206 / 63$ & $1272 / 893$ & 2.30 & $1.71-3.08$ \\
\hline Gao 2009 & $38 / 497$ & $28 / 1174$ & 3.21 & $1.95-5.28$ \\
\hline Mollica 2009d,e & $10 / 3$ & $6 / 23$ & 12.78 & $2.65-61.56$ \\
\hline Rajkumar 2009d,e & $19 / 108$ & $33 / 840$ & 4.48 & $2.46-8.15$ \\
\hline Vanderploeg $2009^{b, e, g}$ & $36 / 43$ & $242 / 505$ & 1.75 & $1.09-2.79$ \\
\hline Bryant 2010b,c,e,f,g & $56 / 265$ & $77 / 419$ & 1.15 & $0.79-1.68$ \\
\hline Pooled OR & & & 2.14 & $1.65-2.77$ \\
\hline \multicolumn{5}{|l|}{ Psychotic disorder } \\
\hline Malaspina 2001 & $22 / 107$ & $22 / 355$ & 3.32 & $1.77-6.23$ \\
\hline Nielsen $2002^{b, e, f}$ & $278 / 7854$ & $3394 / 78,710$ & 0.82 & $0.72-0.93$ \\
\hline Silver 2001a & $12 / 89$ & $349 / 4584$ & 1.77 & $0.96-3.27$ \\
\hline AbdelMalik $2003^{b}$ & $23 / 44$ & $22 / 80$ & 1.90 & $0.95-3.79$ \\
\hline Fann $2004^{a}$ & NA & NA & 1.10 & $0.39-3.10$ \\
\hline Pooled OR & & & 1.57 & $0.83-2.97$ \\
\hline \multicolumn{5}{|l|}{ Bipolar disorder } \\
\hline DelBello $1999 b, c, d, e, g$ & $4 / 17$ & $3 / 13$ & 1.02 & $0.19-5.37$ \\
\hline Malaspina 2001 & $28 / 207$ & $22 / 355$ & 2.18 & $1.22-3.91$ \\
\hline Silver $2001^{a}$ & $6 / 51$ & $355 / 4622$ & 1.53 & $0.65-3.59$ \\
\hline Pooled OR & & & 1.85 & $1.17-2.94$ \\
\hline \multicolumn{5}{|l|}{ Mixed affective disorder } \\
\hline Fann 2004b,f,g & NA & NA & 1.50 & $0.98-2.30$ \\
\hline Nelson 2007b & $76 / 248$ & $318 / 2045$ & 1.97 & $1.49-2.62$ \\
\hline Pooled OR & & & 1.84 & $1.44-2.36$ \\
\hline Pooled OR, psychiatric & & & 2.00 & $1.50-2.66$ \\
\hline Overall pooled OR & & & 1.67 & $1.44-1.93$ \\
\hline $\begin{array}{l}\text { NA = data not available. } \\
\text { a Studies not included in the ov } \\
\text { mutually exclusive. Studies incl } \\
\text { mild TBI criteria for LOC, dthose } \\
\text { 'cohort studies, and hthose anal }\end{array}$ & $\begin{array}{l}\text { sis or pooled neurological/psychiatr } \\
\text { group analyses: bthose with the cle } \\
\text { LOC, ethose requiring at least } 1 \text { mil } \\
\text { isk of repeated TBI. }\end{array}$ & $\begin{array}{l}\text { analyses because diagnostic groups } \\
\text { est interval between TBI and sympto } \\
\text { IBI feature, those with TBI diagnose }\end{array}$ & $\begin{array}{l}\text { thin the } \\
\text { thset, ct } \\
\text { ot basec }\end{array}$ & $\begin{array}{l}\text { tudy were not } \\
\text { ose meeting } \\
\text { on self-reports, }\end{array}$ \\
\hline
\end{tabular}




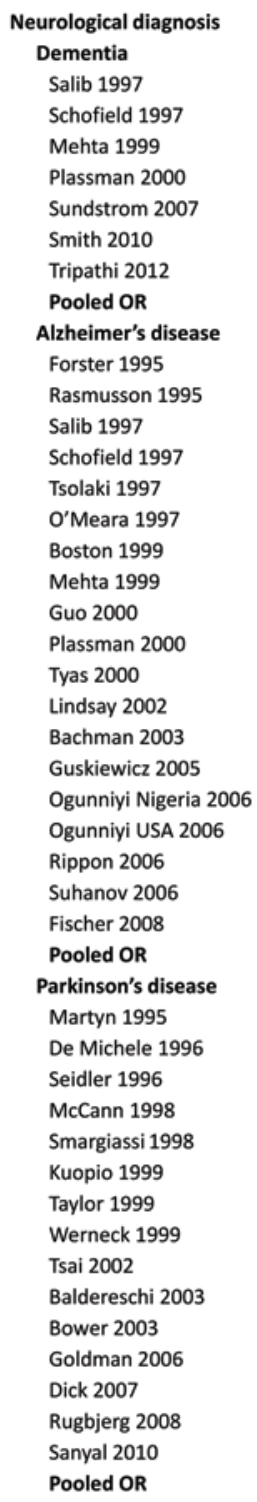
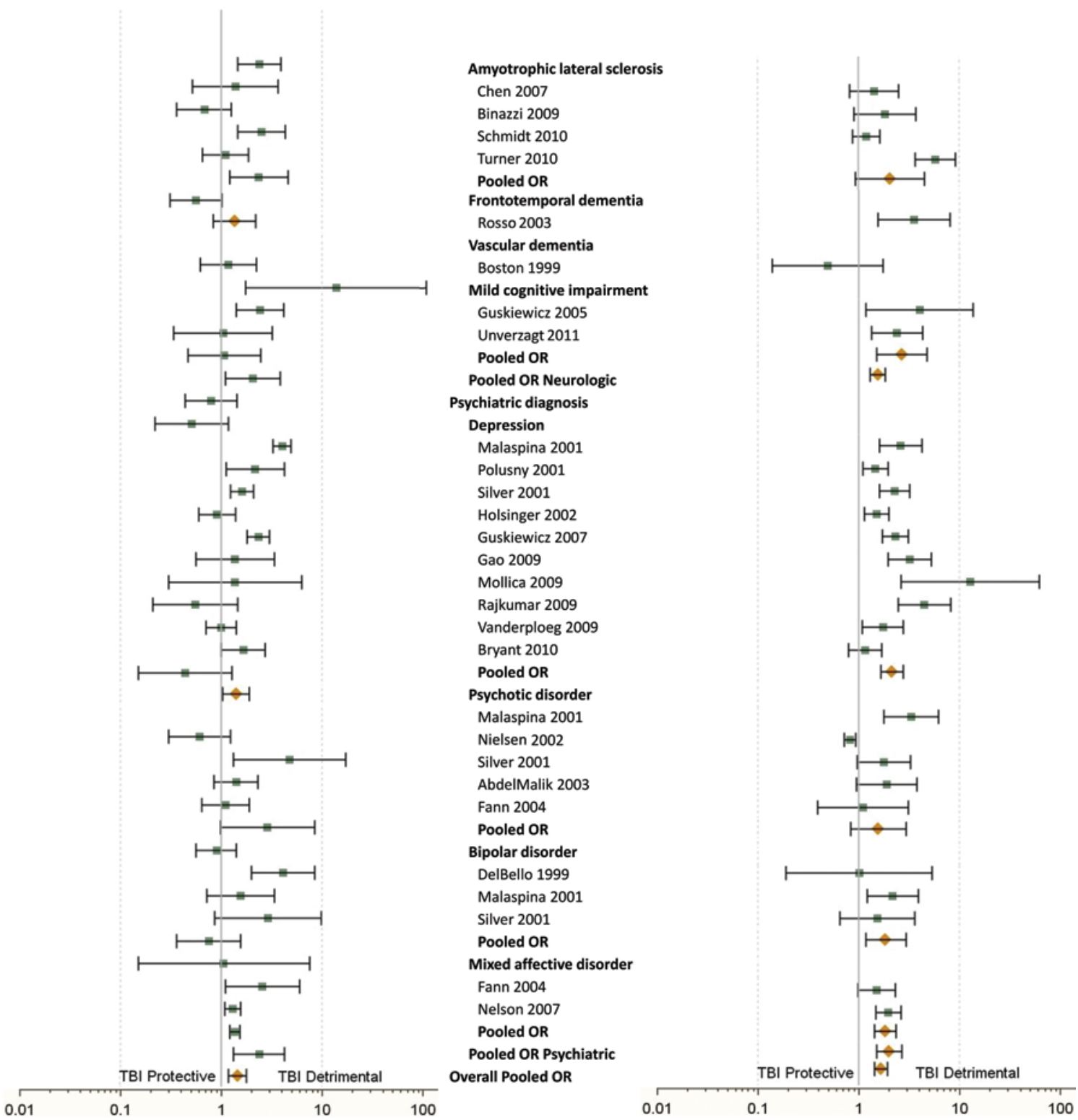

FIG. 2. Individual and pooled ORs for all included studies. Figure is available in color online only.

gression indicated that the effects size (the logarithm of the ORs) was not significantly predicted by the standard error when all studies were included $(\mathrm{F}(1,60)=3.08$, $\mathrm{p}=$ $0.08)$ or when the 3 large sample studies were excluded $(\mathrm{F}(1,57)=1.11, \mathrm{p}=0.30$; Fig. $3 \mathrm{C})$.

\section{Discussion}

This meta-analysis supports an association between prior TBI and later diagnosis of the relevant neurological or psychiatric diseases. This association was found independently for both neurological and psychiatric outcomes. Alzheimer's disease, Parkinson's disease, mild cognitive impairment, depression, mixed affective disorders, and bipolar disorder showed a statistically significant association with prior TBI. The magnitude of effect is comparable across diagnoses, with mild cognitive impairment, depres- sion, and bipolar disorder having the highest OR among results that reached significance. The OR for Alzheimer's disease in this analysis is comparable to the findings of prior meta-analyses. ${ }^{24,58}$ The OR for ALS was among the highest in the study, and there was some evidence of an association of TBI with dementia and psychotic disorders, but these associations did not reach statistical significance.

The overall combined OR for the selected neurological and psychiatric illnesses and for neurological illness independently in individuals with TBI remained significant when including only articles that explicitly specified a minimum 12-month interval between TBI and outcome diagnosis. The magnitude of association with psychiatric illness, however, did not remain significant. These results suggest that there may be a different time course in which psychiatric and neurological symptoms manifest after 


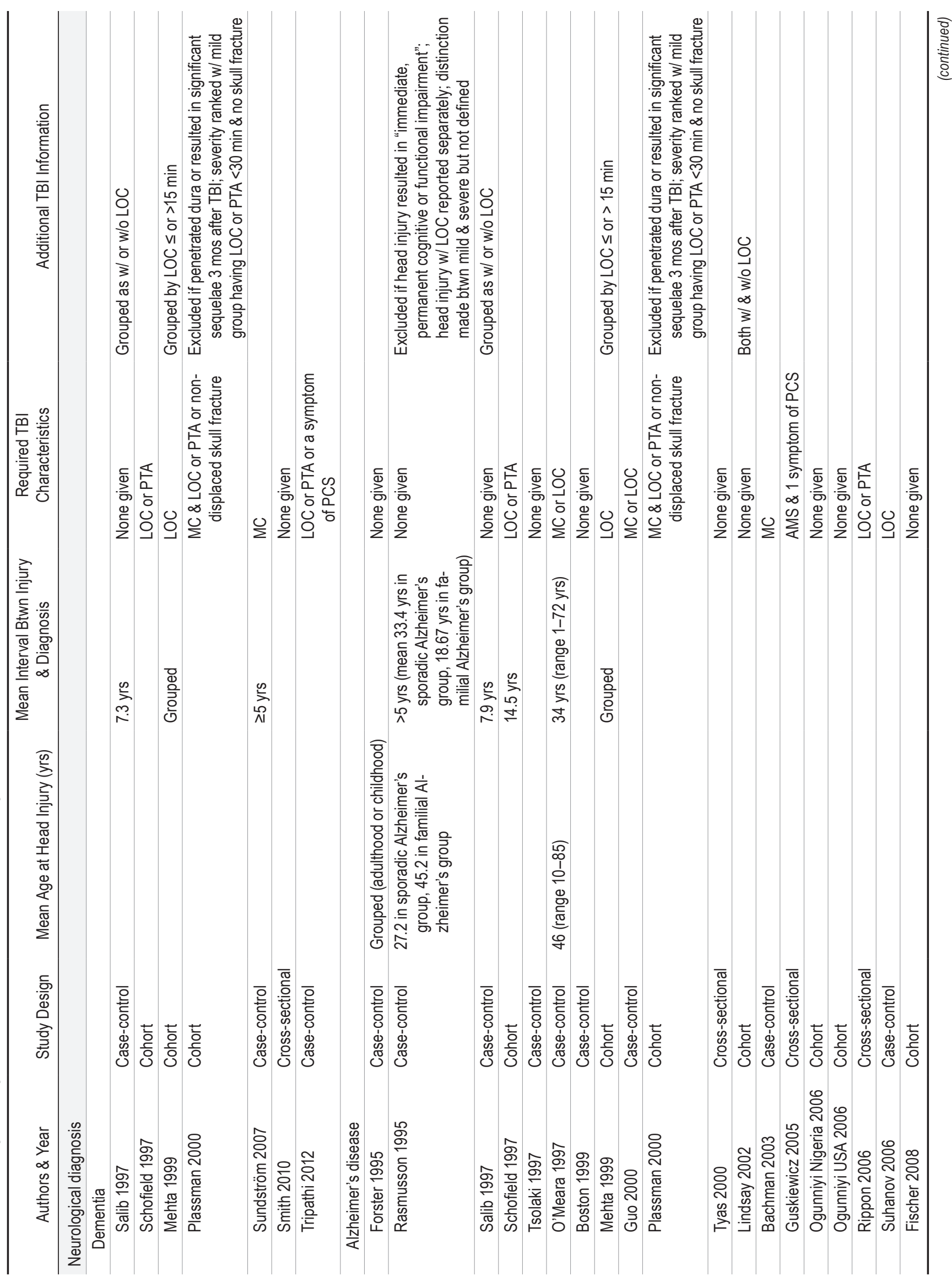




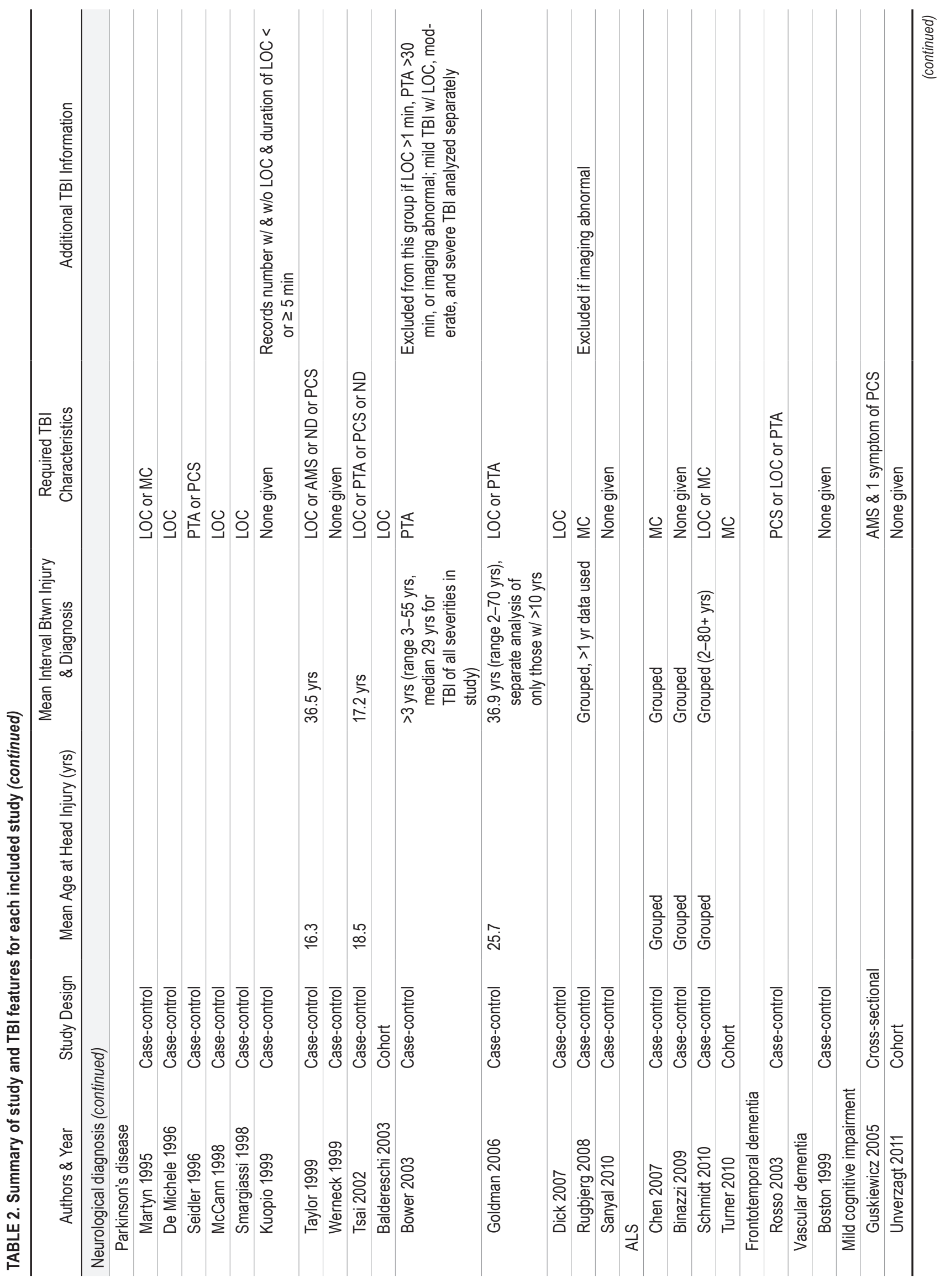




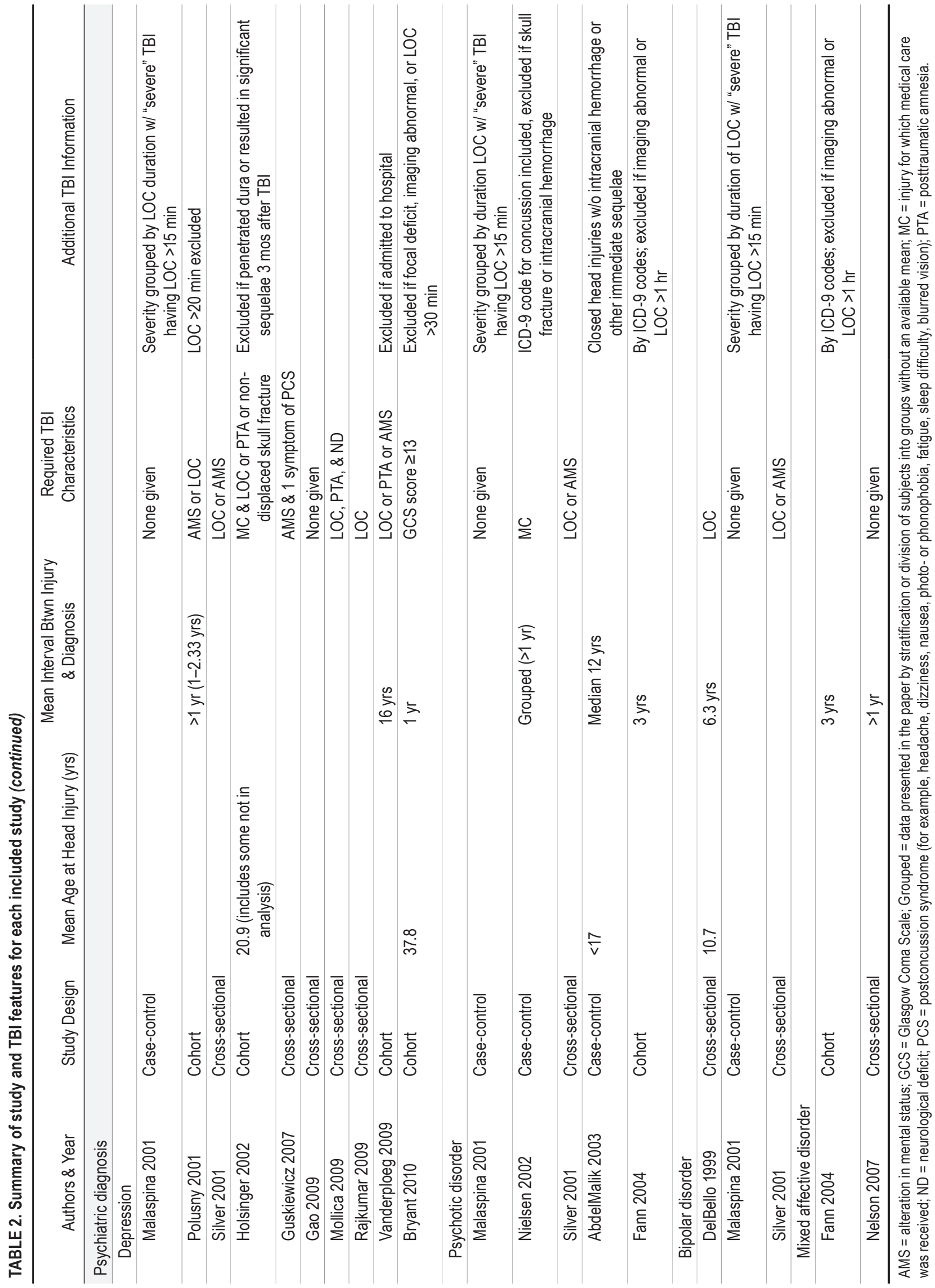


TABLE 3. Results of subgroup analyses

\begin{tabular}{|c|c|c|c|}
\hline Analysis & OR & $95 \% \mathrm{Cl}$ & p Value \\
\hline \multicolumn{4}{|l|}{ Risk of TBI, including only studies w/ clearest interval } \\
\hline All neurological \& psychiatric outcomes & 1.75 & $1.43-2.14$ & $<0.001$ \\
\hline All neurological outcomes & 2.05 & $1.55-2.71$ & $<0.001$ \\
\hline All psychiatric outcomes & 1.38 & $0.95-2.00$ & 0.09 \\
\hline Risk of TBI, including only studies meeting mild TBI requirements for max duration of LOC & 1.54 & $1.18-2.01$ & 0.001 \\
\hline \multicolumn{4}{|l|}{ Risk of TBI, including only studies requiring associated LOC } \\
\hline All neurological \& psychiatric outcomes & 1.69 & $1.18-2.44$ & $<0.01$ \\
\hline All neurological outcomes & 1.33 & $1.00-1.75$ & $<0.05$ \\
\hline All psychiatric outcomes & 4.09 & $1.36-12.32$ & 0.01 \\
\hline \multicolumn{4}{|l|}{ Risk of TBI, including only studies requiring a mild TBI feature } \\
\hline All neurological \& psychiatric outcomes & 1.70 & $1.42-2.05$ & $<0.0001$ \\
\hline All neurological outcomes & 1.67 & $1.36-2.07$ & $<0.0001$ \\
\hline All psychiatric outcomes & 1.81 & $1.23-2.66$ & $<0.01$ \\
\hline \multicolumn{4}{|l|}{ Risk of TBI, eliminating studies w/ TBI diagnosis based on self-report } \\
\hline All neurological \& psychiatric outcomes & 1.62 & $1.14-2.31$ & $<0.01$ \\
\hline All neurological outcomes & 2.38 & $1.01-5.62$ & $<0.05$ \\
\hline All psychiatric outcomes & 1.18 & $0.81-1.71$ & 0.39 \\
\hline \multicolumn{4}{|l|}{ Risk of TBI, including only cohort studies } \\
\hline All neurological \& psychiatric outcomes & 1.38 & $1.02-1.87$ & $<0.05$ \\
\hline All neurological outcomes & 1.27 & $0.72-2.25$ & 0.41 \\
\hline All psychiatric outcomes & 1.45 & $1.23-1.71$ & $<0.0001$ \\
\hline Risk of multiple TBls vs $1 \mathrm{TBI}$ on any outcome diagnosis & 1.10 & $0.72-1.70$ & 0.65 \\
\hline
\end{tabular}

TBI. While psychiatric symptoms are common in the acute phase after mild $\mathrm{TBI}^{6,21,35,40}$ and some of these may be short-lived manifestations of the injury, others may reflect a more sustained susceptibility to mental illness. The results of this study suggest that TBI is a risk factor for both remote psychiatric and neurological disease and are consistent with the possibility that both types of illness arise secondary to a common shared pathological mechanism.

We conducted additional subgroup analyses to determine whether TBI characteristics or methodological factors would influence our findings. The overall OR for TBI remained significant when including only studies that required adherence to typical LOC criteria for mild TBI, the presence of any specific mild TBI symptom, or LOC. Though TBI definitions varied widely among studies, these additional analyses supported an association of mild TBI with the neurological and psychiatric outcomes of interest. A significant OR for combined neurological and psychiatric outcomes was also found when eliminating studies that used self-reported diagnoses of TBI and when including only cohort studies. Though statistical significance was lost when assessing the association with psychiatric outcomes when eliminating self-reports and the odds of neurological outcomes among cohort studies, the magnitudes of the ORs were largely consistent with the main analysis, and the change in significance was probably attributable to the small number of articles in these analyses and the resulting loss of power rather than a reflection of a weaker association due to recall bias, although this cannot be excluded. Our analyses also suggested that the finding of an association with TBI is unlikely to be attributable to publication bias, although low power may affect the publication bias test.

The results of our meta-analysis support an association between illness and a single TBI. A relevant associated question is whether this effect is compounded by multiple TBIs. In our analysis of multiple head traumas, the results do not show strong evidence for elevated odds of illness associated with having more than 1 head trauma versus a single TBI. Given that only 6 studies were included in this analysis, lower power may have influenced these results. More research on the relationship between TBI exposure and diagnostic outcomes is needed.

The magnitude of the OR for TBI in this meta-analysis is relatively modest but comparable to other strongly implicated risk factors. For example, for Alzheimer's disease, the apolipoprotein $E$ e4 allele is associated with an OR of 1.80-9.05:41 and obesity, with an OR of $1.80 .{ }^{4}$ The OR for pesticide exposure and Parkinson's disease is $1.94 .{ }^{66}$ Therefore, the presence of a risk factor in an individual does not indicate an inevitable development of disease. The ORs found in this study suggest that other factors modify an individual's susceptibility to develop a neuropsychiatric disorder after TBI. These factors are largely unknown and thus worthy of further investigation.

The fact that multiple neurodegenerative and psychiatric diagnoses are associated with the same exposure raises questions about possible mechanisms of shared vulnerability. Trauma could predispose the brain to different 

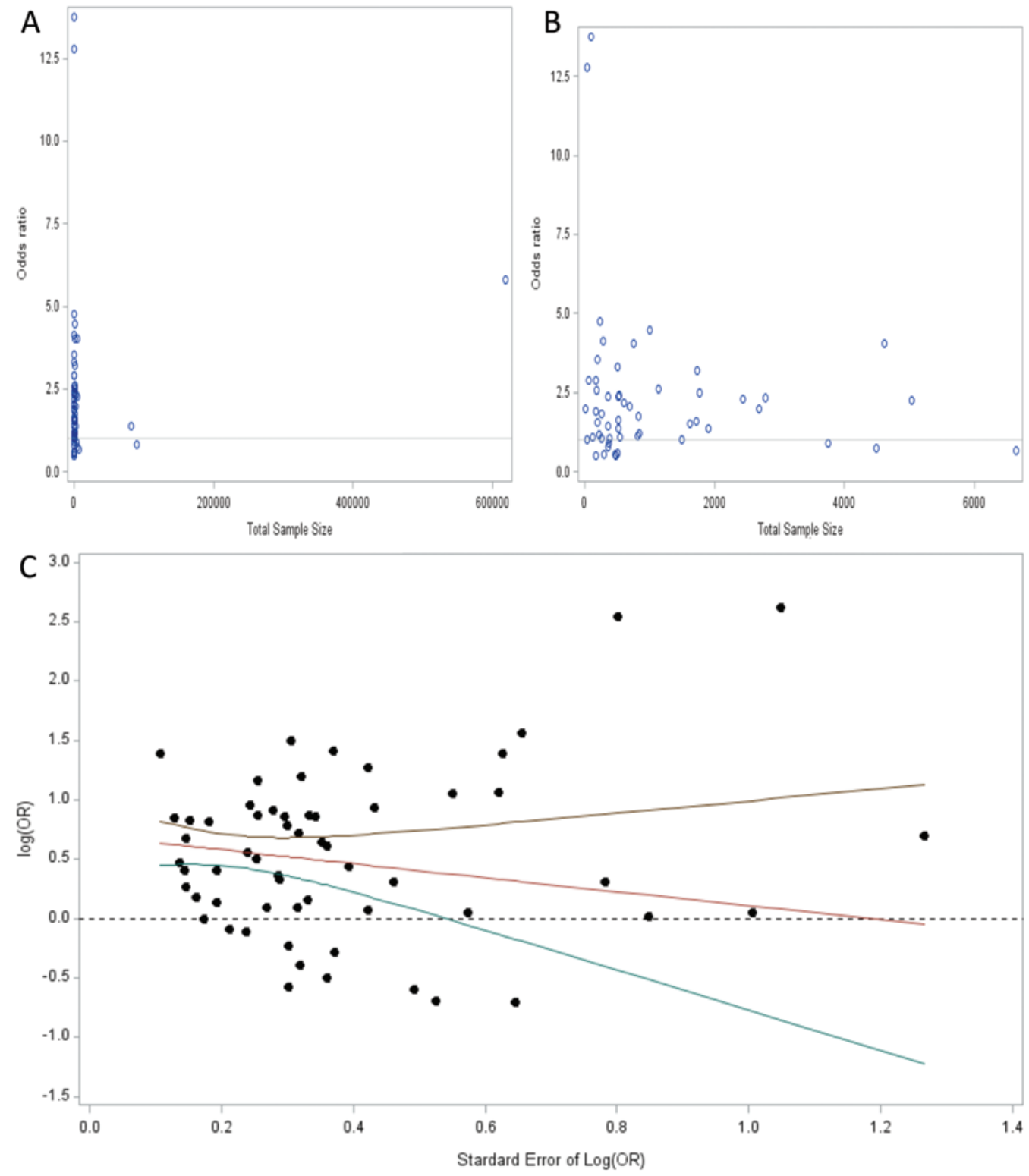

FIG. 3. Publication bias analysis. A: Funnel plot of ORs versus total sample size. B: Funnel plot of ORs versus total sample size after excluding the 3 studies with the largest sample sizes (Rugbjerg 2008, Nielsen 2002, and Turner 2010). C: Plot of the logarithm of the ORs after excluding the 3 largest sample size studies compared with the standard error of the logarithm of the ORs showing a regression line and $95 \% \mathrm{Cl}$ with slope that is not statistically significantly different from 0 . Figure is available in color online only.

types of neurodegeneration through common mechanisms such as oxidative stress and microglial activation ${ }^{77,99}$ or induction of plasma proteins associated with degeneration such as MCP-1. ${ }^{36}$ Trauma might also activate molecular pathways leading to specific degenerative diseases, such as the finding that Alzheimer's disease-associated proteins including beta amyloid, beta secretase, presenilin-1, and caspase- 3 accumulate in axons of brain-injured animals. ${ }^{12}$ Cleaved forms of the tau protein, which is associated with Alzheimer's disease and frontotemporal lobar degeneration, accumulate after trauma, ${ }^{26}$ and tau abnormalities after trauma have been found to be independent of beta amyloid effects. ${ }^{89}$ The nature of the TBI could also influence an individual's clinical presentation. For example, boxers may suffer from more torsional injury that could damage brainstem structures such as the substantia nigra, leading to parkinsonism. ${ }^{82}$ Genetic variation could also help to explain the susceptibility of individuals to late-life effects of TBI. For example, apolipoprotein E, which is associated with the risk of Alzheimer's disease, has shown variable interaction with mild TBI. .0,63,88 $^{5}$

An alternate explanation for the association across diagnostic groups is that the various clinical presentations could be different expressions of a common pathology. ${ }^{28,78}$ Although CTE has been described as a distinct pathological process, its clinical characterization is not clearly established, and case reports suggest cognitive, motor, and psychiatric presentations. This phenotypic variability could 
lead to a diagnosis of dementia, Parkinson's disease, motor neuron disease, or primary psychiatric illness in different individuals. A study of causes of death among retired National Football League players revealed a 3-fold higher rate of death from neurodegenerative disease compared with the typical population frequency, with Alzheimer's disease and ALS being the most overrepresented, ${ }^{44}$ which would be consistent with either a shared vulnerability hypothesis across neurodegenerative diseases or a common pathology. In this meta-analysis we examined clinical, not pathological, studies. Thus, it is unknown whether any of the subjects would have shown characteristic CTE pathology rather than (or in addition to) the more typical neuropathological features associated with their syndromes.

Several of the reviewed articles addressed the association between TBI and clinical outcomes among athletes. These articles assessed the risk of Parkinson's disease among retired Thai traditional boxers,${ }^{46}$ depression and dementia among retired football players, ${ }^{32,33}$ ALS or chronic encephalopathy among soccer players, ${ }^{13,39}$ and chronic TBI in boxers. ${ }^{38}$ Only 2 of the articles ${ }^{32,33}$ that directly evaluated TBI in sports met the strict inclusion criteria for our study. The ability of our meta-analysis to inform questions surrounding the long-term consequences of sports-related mild TBI is therefore limited by restricted data in the existing literature. Further longitudinal studies among athletes with appropriate control groups, characterization of head injuries (including severity, number, and exposure to repetitive subconcussive trauma), and the assessment of late-life neurological and psychiatric outcomes will be needed to address this question.

Several limitations of this meta-analysis warrant consideration. One is the possible bias of the included studies, although we took several steps to mitigate this possibility. Our search strategy included a variety of epidemiological studies that focused on many possible risk factors, not just TBI, and thus capturing negative studies that might otherwise have not been published. Our formal analyses also did not support publication bias. Although the strict inclusion criteria should reduce this possibility, variation in the studies themselves (for example, different criteria for the diagnosis of illness, or comorbid environmental and genetic factors of the study population) limits the generalizability of our results. Variable study quality could also have resulted in heterogeneity, and it is possible that the presence of other confounding factors could have led to the observed association between TBI and later clinical outcomes. For example, patients who sustain a TBI as the result of a fall or motor vehicle accident may have other medical comorbidities (for example, vascular disease or substance abuse) or differences in socioeconomic status that could predispose to neurological or psychiatric illness. Another possibility is that the TBI itself could lead to an injury or a change in lifestyle that could modify the risk for a mood disorder. Finally, ill patients who fall and suffer TBI may also undergo more medical testing and therefore may be more likely to receive one of these neurological or psychiatric diagnoses. Only English-language studies were reviewed, which could have led to the exclusion of some relevant studies. Despite our criteria regarding an interval between TBI and the onset of illness, an alterna- tive explanation for the observed association is that some head injuries may have been early manifestations of neurological or psychiatric disease rather than an independent predisposing factor for illness. The authors of 1 of the included studies concluded this reverse causality was responsible for their findings. ${ }^{71}$ They stratified the interval between TBI and diagnosis and found that the association between TBI and Parkinson's was no longer present when only looking at TBI that occurred more than 10 years prior to diagnosis.

A major strength of our meta-analysis was the inclusion of a variety of different neurological and psychiatric outcomes rather than a single diagnosis. By focusing on diagnoses rather than self-reported symptoms or patient performance on cognitive tests, we assessed outcomes of sufficient magnitude to affect quality of life. The included studies also came from countries around the world, allowing for more generalizable results. The literature search was comprehensive, making this a rigorous examination of the topic.

\section{Conclusions}

This study supports an association of TBI, including mild TBI, with the subsequent development of neurological and psychiatric illness, including Alzheimer's disease, Parkinson's disease, mild cognitive impairment, depression, mixed affective disorders, and bipolar disorder. Because of limitations in and the heterogeneity of existing studies, prospective studies with uniform assessment are needed to confirm this result and determine the risk conferred by the number and severity of TBI in different settings, such as sports or the military.

\section{Acknowledgments}

Dr. Sturm is supported by National Institute on Aging 1K23AG040127. Dr. Peterson is supported by National Cancer Institute Award KM1CA156687. Dr. Boeve receives research support from the National Institute on Aging (P50 AG016574, U01 AG006786, R01 AG032306, and R01 AG041797) and the Mangurian Foundation. Dr. Miller is funded by NIH grants P50AG023501, P01AG019724, P50 AG1657303, and the state of California. Dr. Welsh-Bohmer received funding from the National Institute of Aging (P30 AG28377) and from private donors to the Joseph \& Kathleen Bryan Alzheimer's Disease Center at Duke University.

\section{References}

1. AbdelMalik P, Husted J, Chow EW, Bassett AS: Childhood head injury and expression of schizophrenia in multiply affected families. Arch Gen Psychiatry 60:231-236, 2003

2. Bachman DL, Green RC, Benke KS, Cupples LA, Farrer LA: Comparison of Alzheimer's disease risk factors in white and African American families. Neurology 60:1372-1374, 2003

3. Baldereschi M, Di Carlo A, Vanni P, Ghetti A, Carbonin P, Amaducci L, et al: Lifestyle-related risk factors for Parkinson's disease: a population-based study. Acta Neurol Scand 108:239-244, 2003

4. Beydoun MA, Beydoun HA, Wang Y: Obesity and central obesity as risk factors for incident dementia and its subtypes: a systematic review and meta-analysis. Obes $\operatorname{Rev}$ 9:204-218, 2008

5. Binazzi A, Belli S, Uccelli R, Desiato MT, Talamanca IF, 
Antonini G, et al: An exploratory case-control study on spinal and bulbar forms of amyotrophic lateral sclerosis in the province of Rome. Amyotroph Lateral Scler 10:361-369, 2009

6. Bombardier CH, Fann JR, Temkin NR, Esselman PC, Barber J, Dikmen SS: Rates of major depressive disorder and clinical outcomes following traumatic brain injury. JAMA 303:1938-1945, 2010

7. Boston PF, Dennis MS, Jagger C: Factors associated with vascular dementia in an elderly community population. Int J Geriatr Psychiatry 14:761-766, 1999

8. Bower JH, Maraganore DM, Peterson BJ, McDonnell SK, Ahlskog JE, Rocca WA: Head trauma preceding PD: a casecontrol study. Neurology 60:1610-1615, 2003

9. Bryant RA, O'Donnell ML, Creamer M, McFarlane AC, Clark CR, Silove D: The psychiatric sequelae of traumatic injury. Am J Psychiatry 167:312-320, 2010

10. Carroll LJ, Cassidy JD, Holm L, Kraus J, Coronado VG: Methodological issues and research recommendations for mild traumatic brain injury: the WHO Collaborating Centre Task Force on Mild Traumatic Brain Injury. J Rehabil Med 43 (43 Suppl):113-125, 2004

11. Chen H, Richard M, Sandler DP, Umbach DM, Kamel F: Head injury and amyotrophic lateral sclerosis. Am J Epidemiol 166:810-816, 2007

12. Chen XH, Siman R, Iwata A, Meaney DF, Trojanowski JQ, Smith DH: Long-term accumulation of amyloid-beta, betasecretase, presenilin-1, and caspase-3 in damaged axons following brain trauma. Am J Pathol 165:357-371, 2004

13. Chiò A, Benzi G, Dossena M, Mutani R, Mora G: Severely increased risk of amyotrophic lateral sclerosis among Italian professional football players. Brain 128:472-476, 2005

14. Corsellis JA, Bruton CJ, Freeman-Browne D: The aftermath of boxing. Psychol Med 3:270-303, 1973

15. De Michele G, Filla A, Volpe G, De Marco V, Gogliettino A, Ambrosio G, et al: Environmental and genetic risk factors in Parkinson's disease: a case-control study in southern Italy. Mov Disord 11:17-23, 1996

16. DelBello MP, Soutullo CA, Zimmerman ME, Sax KW, Williams JR, McElroy SL, et al: Traumatic brain injury in individuals convicted of sexual offenses with and without bipolar disorder. Psychiatry Res 89:281-286, 1999

17. Dick FD, De Palma G, Ahmadi A, Scott NW, Prescott GJ, Bennett J, et al: Environmental risk factors for Parkinson's disease and parkinsonism: the Geoparkinson study. Occup Environ Med 64:666-672, 2007

18. Egger M, Davey Smith G, Schneider M, Minder C: Bias in meta-analysis detected by a simple, graphical test. BMJ 315:629-634, 1997

19. Factor SA, Sanchez-Ramos J, Weiner WJ: Trauma as an etiology of parkinsonism: a historical review of the concept. Mov Disord 3:30-36, 1988

20. Fann JR, Burington B, Leonetti A, Jaffe K, Katon WJ, Thompson RS: Psychiatric illness following traumatic brain injury in an adult health maintenance organization population. Arch Gen Psychiatry 61:53-61, 2004

21. Fedoroff JP, Starkstein SE, Forrester AW, Geisler FH, Jorge RE, Arndt SV, et al: Depression in patients with acute traumatic brain injury. Am J Psychiatry 149:918-923, 1992

22. Fischer P, Zehetmayer S, Jungwirth S, Weissgram S, Krampla W, Hinterberger M, et al: Risk factors for Alzheimer dementia in a community-based birth cohort at the age of 75 years. Dement Geriatr Cogn Disord 25:501-507, 2008

23. Fleiss JL, Levin BA, Paik MC: Statistical Methods for Rates and Proportions. New York: Wiley, 2003

24. Fleminger S, Oliver DL, Lovestone S, Rabe-Hesketh S, Giora A: Head injury as a risk factor for Alzheimer's disease: the evidence 10 years on; a partial replication. J Neurol Neurosurg Psychiatry 74:857-862, 2003
25. Forster DP, Newens AJ, Kay DW, Edwardson JA: Risk factors in clinically diagnosed presenile dementia of the Alzheimer type: a case-control study in northern England. J Epidemiol Community Health 49:253-258, 1995

26. Gabbita SP, Scheff SW, Menard RM, Roberts K, Fugaccia I, Zemlan FP: Cleaved-tau: a biomarker of neuronal damage after traumatic brain injury. J Neurotrauma 22:83-94, 2005

27. Gao S, Jin Y, Unverzagt FW, Liang C, Hall KS, Ma F, et al: Correlates of depressive symptoms in rural elderly Chinese. Int J Geriatr Psychiatry 24:1358-1366, 2009

28. Gavett BE, Stern RA, Cantu RC, Nowinski CJ, McKee AC: Mild traumatic brain injury: a risk factor for neurodegeneration. Alzheimers Res Ther 2:18, 2010

29. Goldman SM, Tanner CM, Oakes D, Bhudhikanok GS, Gupta A, Langston JW: Head injury and Parkinson's disease risk in twins. Ann Neurol 60:65-72, 2006

30. Goldstein LE, Fisher AM, Tagge CA, Zhang XL, Velisek L, Sullivan JA, et al: Chronic traumatic encephalopathy in blastexposed military veterans and a blast neurotrauma mouse model. Sci Transl Med 4:134ra60, 2012

31. Guo Z, Cupples LA, Kurz A, Auerbach SH, Volicer L, Chui $\mathrm{H}$, et al: Head injury and the risk of AD in the MIRAGE study. Neurology 54:1316-1323, 2000

32. Guskiewicz KM, Marshall SW, Bailes J, McCrea M, Cantu $\mathrm{RC}$, Randolph C, et al: Association between recurrent concussion and late-life cognitive impairment in retired professional football players. Neurosurgery 57:719-726, 2005

33. Guskiewicz KM, Marshall SW, Bailes J, McCrea M, Harding HP Jr, Matthews A, et al: Recurrent concussion and risk of depression in retired professional football players. Med Sci Sports Exerc 39:903-909, 2007

34. Hedges LV, Olkin I: Statistical Methods for Meta-Analysis. Orlando, FL: Academic Press, 1985

35. Hibbard MR, Uysal S, Kepler K, Bogdany J, Silver J: Axis I psychopathology in individuals with traumatic brain injury. J Head Trauma Rehabil 13:24-39, 1998

36. Ho L, Zhao W, Dams-O'Connor K, Tang CY, Gordon W, Peskind ER, et al: Elevated plasma MCP-1 concentration following traumatic brain injury as a potential "predisposition" factor associated with an increased risk for subsequent development of Alzheimer's disease. J Alzheimers Dis 31:301-313, 2012

37. Holsinger T, Steffens DC, Phillips C, Helms MJ, Havlik RJ, Breitner JC, et al: Head injury in early adulthood and the lifetime risk of depression. Arch Gen Psychiatry 59:17-22, 2002

38. Jordan BD, Relkin NR, Ravdin LD, Jacobs AR, Bennett A, Gandy S: Apolipoprotein E epsilon4 associated with chronic traumatic brain injury in boxing. JAMA 278:136-140, 1997

39. Jordan SE, Green GA, Galanty HL, Mandelbaum BR, Jabour BA: Acute and chronic brain injury in United States National Team soccer players. Am J Sports Med 24:205-210, 1996

40. Jorge RE, Robinson RG, Starkstein SE, Arndt SV: Depression and anxiety following traumatic brain injury. J Neuropsychiatry Clin Neurosci 5:369-374, 1993

41. Jun G, Naj AC, Beecham GW, Wang LS, Buros J, Gallins PJ, et al: Meta-analysis confirms CR1, CLU, and PICALM as Alzheimer disease risk loci and reveals interactions with APOE genotypes. Arch Neurol 67:1473-1484, 2010

42. Kay T, Harrington DE, Adams R, Anderson T, Berrol S, Cicerone K, et al: Definition of mild traumatic brain injury. $\mathbf{J}$ Head Trauma Rehabil 8:86-87, 1993

43. Kuopio AM, Marttila RJ, Helenius H, Rinne UK: Environmental risk factors in Parkinson's disease. Mov Disord 14:928-939, 1999

44. Lehman EJ, Hein MJ, Baron SL, Gersic CM: Neurodegenerative causes of death among retired National Football League players. Neurology 79:1970-1974, 2012

45. Lindsay J, Laurin D, Verreault R, Hébert R, Helliwell B, Hill $\mathrm{GB}$, et al: Risk factors for Alzheimer's disease: a prospective 
analysis from the Canadian Study of Health and Aging. Am J Epidemiol 156:445-453, 2002

46. Lolekha P, Phanthumchinda K, Bhidayasiri R: Prevalence and risk factors of Parkinson's disease in retired Thai traditional boxers. Mov Disord 25:1895-1901, 2010

47. Malaspina D, Goetz RR, Friedman JH, Kaufmann CA, Faraone SV, Tsuang M, et al: Traumatic brain injury and schizophrenia in members of schizophrenia and bipolar disorder pedigrees. Am J Psychiatry 158:440-446, 2001

48. Martland HS: Punch drunk. JAMA 91:1103-1107, 1928

49. Martyn CN, Osmond C: Parkinson's disease and the environment in early life. J Neurol Sci 132:201-206, 1995

50. Mayeux R, Ottman R, Maestre G, Ngai C, Tang MX, Ginsberg H, et al: Synergistic effects of traumatic head injury and apolipoprotein-epsilon 4 in patients with Alzheimer's disease. Neurology 45:555-557, 1995

51. McCann SJ, LeCouteur DG, Green AC, Brayne C, Johnson AG, Chan D, et al: The epidemiology of Parkinson's disease in an Australian population. Neuroepidemiology 17:310 317, 1998

52. McKee AC, Cantu RC, Nowinski CJ, Hedley-Whyte ET, Gavett $\mathrm{BE}$, Budson $\mathrm{AE}$, et al: Chronic traumatic encephalopathy in athletes: progressive tauopathy after repetitive head injury. J Neuropathol Exp Neurol 68:709-735, 2009

53. McKee AC, Gavett BE, Stern RA, Nowinski CJ, Cantu RC, Kowall NW, et al: TDP-43 proteinopathy and motor neuron disease in chronic traumatic encephalopathy. J Neuropathol Exp Neurol 69:918-929, 2010

54. McKee AC, Stern RA, Nowinski CJ, Stein TD, Alvarez VE, Daneshvar DH, et al: The spectrum of disease in chronic traumatic encephalopathy. Brain 136:43-64, 2013

55. Mehta KM, Ott A, Kalmijn S, Slooter AJ, van Duijn CM, Hofman A, et al: Head trauma and risk of dementia and Alzheimer's disease: The Rotterdam Study. Neurology 53:1959-1962, 1999

56. Moher D, Liberati A, Tetzlaff J, Altman DG: Preferred reporting items for systematic reviews and meta-analyses: the PRISMA statement. PLoS Med 6:e1000097, 2009

57. Mollica RF, Lyoo IK, Chernoff MC, Bui HX, Lavelle J, Yoon SJ, et al: Brain structural abnormalities and mental health sequelae in South Vietnamese ex-political detainees who survived traumatic head injury and torture. Arch Gen Psychiatry 66:1221-1232, 2009

58. Mortimer JA, van Duijn CM, Chandra V, Fratiglioni L, Graves AB, Heyman A, et al: Head trauma as a risk factor for Alzheimer's disease: a collaborative re-analysis of casecontrol studies. Int J Epidemiol 20 (Suppl 2):S28-S35, 1991

59. National Center for Injury Prevention and Control: Report to Congress on Mild Traumatic Brain Injury in the United States: Steps to Prevent a Serious Public Health Problem. Atlanta: Centers for Disease Control and Prevention, 2003

60. Nelson LA, Rhoades DA, Noonan C, Manson SM: Traumatic brain injury and mental health among two American Indian populations. J Head Trauma Rehabil 22:105-112, 2007

61. Nielsen AS, Mortensen PB, O'Callaghan E, Mors O, Ewald $\mathrm{H}$ : Is head injury a risk factor for schizophrenia? Schizophr Res 55:93-98, 2002

62. Ogunniyi A, Hall KS, Gureje O, Baiyewu O, Gao S, Unverzagt FW, et al: Risk factors for incident Alzheimer's disease in African Americans and Yoruba. Metab Brain Dis 21:235-240, 2006

63. O'Meara ES, Kukull WA, Sheppard L, Bowen JD, McCormick WC, Teri L, et al: Head injury and risk of Alzheimer's disease by apolipoprotein E genotype. Am J Epidemiol 146:373-384, 1997

64. Plassman BL, Havlik RJ, Steffens DC, Helms MJ, Newman TN, Drosdick D, et al: Documented head injury in early adulthood and risk of Alzheimer's disease and other dementias. Neurology 55:1158-1166, 2000
65. Polusny MA, Kehle SM, Nelson NW, Erbes CR, Arbisi PA, Thuras P: Longitudinal effects of mild traumatic brain injury and posttraumatic stress disorder comorbidity on postdeployment outcomes in National Guard soldiers deployed to Iraq. Arch Gen Psychiatry 68:79-89, 2011

66. Priyadarshi A, Khuder SA, Schaub EA, Shrivastava S: A meta-analysis of Parkinson's disease and exposure to pesticides. Neurotoxicology 21:435-440, 2000

67. Rajkumar AP, Thangadurai P, Senthilkumar P, Gayathri K, Prince M, Jacob KS: Nature, prevalence and factors associated with depression among the elderly in a rural south Indian community. Int Psychogeriatr 21:372-378, 2009

68. Rasmusson DX, Brandt J, Martin DB, Folstein MF: Head injury as a risk factor in Alzheimer's disease. Brain Inj 9:213-219, 1995

69. Rippon GA, Tang MX, Lee JH, Lantigua R, Medrano M, Mayeux R: Familial Alzheimer disease in Latinos: interaction between APOE, stroke, and estrogen replacement. Neurology 66:35-40, 2006

70. Rosso SM, Landweer EJ, Houterman M, Donker Kaat L, van Duijn CM, van Swieten JC: Medical and environmental risk factors for sporadic frontotemporal dementia: a retrospective case-control study. J Neurol Neurosurg Psychiatry 74:1574-1576, 2003

71. Rugbjerg K, Ritz B, Korbo L, Martinussen N, Olsen JH: Risk of Parkinson's disease after hospital contact for head injury: population based case-control study. BMJ 337:a2494, 2008

72. Salib E, Hillier V: Head injury and the risk of Alzheimer's disease: a case control study. Int J Geriatr Psychiatry 12:363-368, 1997

73. Sanyal J, Chakraborty DP, Sarkar B, Banerjee TK, Mukherjee SC, Ray BC, et al: Environmental and familial risk factors of Parkinsons disease: case-control study. Can J Neurol Sci 37:637-642, 2010

74. Schmidt S, Kwee LC, Allen KD, Oddone EZ: Association of ALS with head injury, cigarette smoking and APOE genotypes. J Neurol Sci 291:22-29, 2010

75. Schofield PW, Tang M, Marder K, Bell K, Dooneief G, Chun $M$, et al: Alzheimer's disease after remote head injury: an incidence study. J Neurol Neurosurg Psychiatry 62:119-124, 1997

76. Seidler A, Hellenbrand W, Robra BP, Vieregge P, Nischan P, Joerg J, et al: Possible environmental, occupational, and other etiologic factors for Parkinson's disease: a case-control study in Germany. Neurology 46:1275-1284, 1996

77. Shitaka Y, Tran HT, Bennett RE, Sanchez L, Levy MA, Dikranian K, et al: Repetitive closed-skull traumatic brain injury in mice causes persistent multifocal axonal injury and microglial reactivity. J Neuropathol Exp Neurol 70:551567, 2011

78. Shively S, Scher AI, Perl DP, Diaz-Arrastia R: Dementia resulting from traumatic brain injury: what is the pathology? Arch Neurol 69:1245-1251, 2012

79. Silver JM, Kramer R, Greenwald S, Weissman M: The association between head injuries and psychiatric disorders: findings from the New Haven NIMH Epidemiologic Catchment Area Study. Brain Inj 15:935-945, 2001

80. Smargiassi A, Mutti A, De Rosa A, De Palma G, Negrotti A, Calzetti S: A case-control study of occupational and environmental risk factors for Parkinson's disease in the EmiliaRomagna region of Italy. Neurotoxicology 19:709-712, 1998

81. Smith K, Flicker L, Dwyer A, Atkinson D, Almeida OP, Lautenschlager NT, et al: Factors associated with dementia in Aboriginal Australians. Aust N Z J Psychiatry 44:888-893, 2010

82. Stern RA, Daneshvar DH, Baugh CM, Seichepine DR, Montenigro PH, Riley DO, et al: Clinical presentation of chronic traumatic encephalopathy. Neurology 81:1122-1129, 2013

83. Sterne JA, Egger M: Funnel plots for detecting bias in meta- 
analysis: guidelines on choice of axis. J Clin Epidemiol 54:1046-1055, 2001

84. Stroup DF, Berlin JA, Morton SC, Olkin I, Williamson GD, Rennie D, et al: Meta-analysis of observational studies in epidemiology: a proposal for reporting. Meta-analysis Of Observational Studies in Epidemiology (MOOSE) group. JAMA 283:2008-2012, 2000

85. Suhanov AV, Pilipenko PI, Korczyn AD, Hofman A, Voevoda MI, Shishkin SV, et al: Risk factors for Alzheimer's disease in Russia: a case-control study. Eur J Neurol 13:990-995, 2006

86. Sundström A, Nilsson LG, Cruts M, Adolfsson R, Van Broeckhoven C, Nyberg L: Increased risk of dementia following mild head injury for carriers but not for non-carriers of the APOE epsilon4 allele. Int Psychogeriatr 19:159-165, 2007

87. Taylor CA, Saint-Hilaire MH, Cupples LA, Thomas CA, Burchard AE, Feldman RG, et al: Environmental, medical, and family history risk factors for Parkinson's disease: a New England-based case control study. Am J Med Genet 88:742749, 1999

88. Terrell TR, Bostick RM, Abramson R, Xie D, Barfield W, Cantu R, et al: APOE, APOE promoter, and Tau genotypes and risk for concussion in college athletes. Clin J Sport Med 18:10-17, 2008

89. Tran HT, LaFerla FM, Holtzman DM, Brody DL: Controlled cortical impact traumatic brain injury in 3xTg-AD mice causes acute intra-axonal amyloid-b accumulation and independently accelerates the development of tau abnormalities. J Neurosci 31:9513-9525, 2011

90. Tripathi M, Vibha D, Gupta P, Bhatia R, Srivastava MV, Vivekanandhan S, et al: Risk factors of dementia in North India: a case-control study. Aging Ment Health 16:228-235, 2012

91. Tsai CH, Lo SK, See LC, Chen HZ, Chen RS, Weng YH, et al: Environmental risk factors of young onset Parkinson's disease: a case-control study. Clin Neurol Neurosurg 104:328-333, 2002

92. Tsolaki M, Fountoulakis K, Chantzi E, Kazis A: Risk factors for clinically diagnosed Alzheimer's disease: a case-control study of a Greek population. Int Psychogeriatr 9:327-341, 1997

93. Turner MR, Abisgold J, Yeates DG, Talbot K, Goldacre MJ: Head and other physical trauma requiring hospitalisation is not a significant risk factor in the development of ALS. J Neurol Sci 288:45-48, 2010

94. Tyas SL, Pederson LL, Koval JJ: Is smoking associated with the risk of developing Alzheimer's disease? Results from three Canadian data sets. Ann Epidemiol 10:409-416, 2000
95. Unverzagt FW, Ogunniyi A, Taler V, Gao S, Lane KA, Baiyewu $\mathrm{O}$, et al: Incidence and risk factors for cognitive impairment no dementia and mild cognitive impairment in African Americans. Alzheimer Dis Assoc Disord 25:4-10, 2011

96. van Reekum R, Cohen T, Wong J: Can traumatic brain injury cause psychiatric disorders? J Neuropsychiatry Clin Neurosci 12:316-327, 2000

97. Vanderploeg RD, Belanger HG, Curtiss G: Mild traumatic brain injury and posttraumatic stress disorder and their associations with health symptoms. Arch Phys Med Rehabil 90:1084-1093, 2009

98. Werneck AL, Alvarenga H: Genetics, drugs and environmental factors in Parkinson's disease. A case-control study. Arq Neuropsiquiatr 57 (2B):347-355, 1999

99. Zhang QG, Laird MD, Han D, Nguyen K, Scott E, Dong Y, et al: Critical role of NADPH oxidase in neuronal oxidative damage and microglia activation following traumatic brain injury. PLoS One 7:e34504, 2012

\section{Disclosure}

Drs. Perry, Pieper, Berger, Guskiewicz, Kramer, and Bullock report no competing interests. Dr. Boeve has served as an investigator for clinical trials sponsored by Cephalon Inc., Allon Pharmaceuticals, and GE Healthcare. He receives royalties from the publication of a book entitled Behavioral Neurology of Dementia (Cambridge Medicine, 2009). He has received honoraria from the American Academy of Neurology. He serves on the Scientific Advisory Board of the Tau Consortium. Dr. Welsh-Bohmer received funding from Takeda and Zinfandel Pharmaceutical companies.

\section{Author Contributions}

Conception and design: Perry, Sturm, Boeve, Miller, Guskiewicz, Berger, Kramer, Welsh-Bohmer. Acquisition of data: Perry, Sturm, Bullock. Analysis and interpretation of data: Perry, Sturm, Peterson, Pieper. Drafting the article: Perry, Sturm, Peterson, Pieper. Critically revising the article: Bullock, Boeve, Miller, Guskiewicz, Berger, Kramer, Welsh-Bohmer. Reviewed submitted version of manuscript: all authors. Approved the final version of the manuscript on behalf of all authors: Perry. Statistical analysis: Peterson, Pieper.

\section{Correspondence}

David C. Perry, MD, University of California, San Francisco, Memory and Aging Center MC: 1207, 675 Nelson Rising Lane, Suite 190, San Francisco, CA 94158. email: dperry@memory. ucsf.edu. 